\title{
Д.А. Коняев
}

\section{Взаимосвязь показателей интерлейкинового профиля и оксидантной системы крови у пожилых больных возрастной макулярной дегенерацией с поздней стадией}

Тамбовский филиал Федерального государственного автономного учреждения межотраслевой научно-технический комплекс «Микрохирургия глаза имени академика С.Н. Фёдорова», ул. Рассказовское шоссе, д.1, г. Тамбов, 392000, Российская Федерация Автор для переписки: Д.А. Коняев (vitalaxen@ mail.ru)

\begin{abstract}
Аннотация
Актуальность: В пожилом возрасте возрастная макулярная дегенерация имеет высокую распространённость и часто вызывает снижение и полную потерю зрения. Однако иммунологические механизмы развития данной патологии и их связь с изменениями оксидантной системы у пожилых больных остаются недостаточно изученными. Цель исследования: Анализ взаимосвязей показателей интерлейкинового профиля и оксидантной системы сыворотки крови у пожилых больных возрастной макулярной дегенерацией с поздней стадией (AREDS4). Материалы и методы: Уровень сывороточных интерлейкинов и показатели оксидантной системы изучены у 57 больных в возрасте 60-74 года с возрастной макулярной дегенерацией 4-й стадии. Контролем служили 52 человека аналогичного возраста без указанной выше патологии. Содержание интерлейкинов определяли на проточном цитометре BD FACS Canto 2, а перекисное окисление липидов - на спектрофотометре СФ-16. Результаты: Установлено достоверное повышение анализированных сывороточных интерлейкинов и в большей степени IL-1 $\beta$, IL-8 группы больных с возрастной макулярной дегенерациией в сравнении с возрастным контролем. Содержание противовоспалительных интерлейкинов и интерферонов- $\alpha$, у достоверно снизилось у пациентов с рассматриваемым заболеванием, уровень продуктов перекисного окисления липидов статистические значило повысился. Между противовоспалительными интерлейкинами и показателями оксидантной системы выявлены обратные корреляционные связи, с изменением противовоспалительных интерлейкинов и показателей свободнорадикального окисления имеются обратные связи. Заключение: В результате проведенного исследования установлены особенности интерлейкинового профиля и оксидантной системы сыворотки крови у пожилых больных возрастной макулярной дегенерацией с поздней стадией, учет которых позволит рационализировать диагностику и патогенетическую терапию при возрастной макулярной дегенерации у пожилых.
\end{abstract}

Ключевые слова: интерлейкины крови; оксидантная система; возрастная макулярная дегенерация; пожилые

Для цитирования: Коняев ДА. Взаимосвязь показателей интерлейкинового профиля и оксидантной системы крови у пожилых больных возрастной макулярной дегенерацией с поздней стадией. Научные результаты биомедицинских исследований. 2020;6(1):118-125. DOI: 10.18413/2658-6533-2020-6-1-0-10 


\section{Dmitry A. Konyaev}

Interrelation of interleukin profile and the blood oxidant system in elderly patients with late-stage age-related macular degeneration

\author{
Academician S.N. Fedorov Eye Microsurgery Complex, Tambov Branch, \\ 1 Rasskazovskoe Highway, Tambov, 392000, Russia \\ Corresponding author: Dmitry A. Konyaev (vitalaxen@mail.ru)
}

\begin{abstract}
Background: In the elderly, age-related macular degeneration has a high prevalence and often causes a decrease and complete loss of vision. However, immunological mechanisms of development of this pathology and their relationship with changes in the oxidant system in elderly patients remain insufficiently studied. The aim of the study: To analyze the relationship between interleukin profile and the serum oxidant system in elderly patients with late-stage age-related macular degeneration (AREDS4). Materials and methods: Serum interleukin levels and the oxidant system parameters were studied in 57 patients aged 60-74 years with stage 4 age-related macular degeneration. The control group included 52 people of the same age without the above pathology. The content of interleukins was determined on the flow cytometer BD FACS Canto 2, and lipid peroxidation-on the spectrophotometer SF-16. Results: There was a significant increase in the analyzed serum interleukins and, to a greater extent, IL-1 $\beta$, IL-8 in the group of patients with age-related macular degeneration in comparison with the age control. The content of anti-inflammatory interleukins and interferons- $\alpha, \gamma$ significantly decreased in patients with this disease, the level of lipid peroxidation products significantly increased. Inverse correlations were found between anti-inflammatory interleukins and indicators of the oxidant system. There are inverse correlations with changes in anti-inflammatory interleukins and indicators of free radical oxidation. Conclusion: As a result of the study, the features of the interleukin profile and the oxidative system of blood serum in elderly patients with advanced macular degeneration with advanced stage have been established that will enable to rationalize the diagnosis and pathogenetic therapy for age-related macular degeneration in the elderly.
\end{abstract}

Keywords: blood interleukins; oxidant system; age-related macular degeneration; elderly

For citation: Konyaev DA. Interrelation of interleukin profile and the blood oxidant system in elderly patients with late-stage age-related macular degeneration. Research Results in Biomedicine. 2020;6(1):118-125. (In Russian) DOI: 10.18413/2658-65332020-6-1-0-10

Введение. В пожилом возрасте возрастная макулярная дегенерация( ВМД) считается распространённой патологией и ведущей причиной в структуре патологии органа зрения и слепоты [1-5]. По данным Всемирной организации здравоохранения количество больных ВМД в мире стремительно возрастает и по прогнозным оценкам к 2020 г. уровень заболеваемости ВМД увеличится на треть [6, 7]. ВМД является наиболее распространённым заболеванием в США, где число пациентов составляет около 3 миллионов [8]. В Китае высокая заболеваемость ВМД служит основной причиной инвалидности [5]. В Швеции среди жителей в возрасте 40 лет и ставшие в течение исследуемого периода выявлено 707341 случаев заболеваний глаза и 20,9\% 
приходилось на ВМД, что соответствует второму месту после катаракты [9]. Среди финского населения ВМД обнаружена в $13,8 \%$ случаев у населения старше 30 лет [10]. У пожилых людей в Непале ВМД достигает $38,4 \%[11,12]$. В России заболеваемость ВМД составляет более 150 случаев на 10000 населения. Проведенное нами ранее исследование выявило повышение частоты ВМД в Тамбовской области с 1,38 случаев в 2010 г. до 2,28 случаев на 10000 населения в 2015 г. [13]. В связи с увеличением доли пожилых в структуре общества негативная тенденция в уровне ВМД сохранится, что, безусловно указывает на приоритетность исследования гериатрических аспектов ВМД [2].

Актуальным направлением в изучении ВМД, наряду с генетическими факторами, атеросклерозом и др., называется анализ патогенетических механизмов на уровне иммунных процессов. Только в последние годы показана важная роль нарушений иммунологических реакций в возникновении и генезе ВМД, выполненных преимущественно в экспериментальных условиях $[14,15]$. Местные и системные нарушения интерлейкинового профиля изучены в основном на ранних стадиях ВМД. Вместе с тем исследования интерлейкинов, как важнейшего звена иммунорегуляции, при ВМД немногочисленны [3] и практически не проводились у пациентов пожилого возраста (60-75лет) с поздней стадией заболевания - AREDS 4 (AgeRelated Eye Diasease Study). B научных публикациях также отсутствуют сведения о взаимосвязи сывороточных интерлейкинов и показателей оксидантной системы, являющихся важнейшим фактором в патогенезе ВМД [16].

Материал и методы исследования. Исследование проведено в Тамбовском филиале МНТК «Микрохирургия глаза имени академика С.Н. Фёдорова» в 20162018 гг. В клинических условиях сформированы основная группа в количестве 57 больных в возрасте 60-74 года с ВМД 4-й стадии (средний возраст $69,4 \pm 2,4$ года) и контрольная группа в количестве 52 человек без ВМД аналогичного возраста (средний возраст 68,8 2 2,1 лет) $(\mathrm{P}>0,05)$.

Исследуемые группы не имели статистически значимых различий по частоте сопутствующих заболеваний и основным биохимическим показателям (табл. 1). Среди сопутствующей патологии в обеих группах преобладала ИБС, болезни органов дыхания. Высокую распространенность как в основой группе, так и в контроле имела мочекаменная болезнь. Средние значения основных биохимических показателей соответствовали референсным в обеих группах.

Критериями невключения в основную и контрольную группы являлись наличие: возраст более 74 лет, артериальной гипертензии II-III степени, абдоминального ожирения, метаболического синдрома, дислипидемии, индекса атерогенности более 3 ммоль/л, аутоиммунных заболеваний, острого воспалительного процесса любой локализации, злокачественных новообразований.

Среди больных основной и контрольной групп гериатрические синдромы встречались соответственно со следующей частотой: деменция - $1,8 \%$ и $3,5 \%$ синдромом мальнутриции $-1,8 \%$ и $3,8 \%$ от всех больных в группе, когнитивный дефицит по Монреальской шкале (Montreal - Cogni-

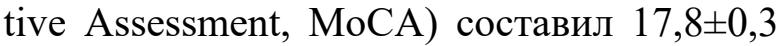
балла и 16,4 $\pm 0,5$ балла при норме 26-30 баллов (Р>0,05 во всех случаях).

Содержание интерлейкинов в сыворотке крови определяли на проточном цитометре BD FACS Canto 2 посредством набора CBA (BD Biosciences, USA). При определении продуктов перекисного окисления липидов использовали спектрофотометр СФ-16. Выполнение исследования проводилось в соответствии с соблюдением этических принципов и стандартов надлежащей клинической практике (Good Clinical Praktike). У всех пациентов получено письменное информированное согласие на использование и обработку данных в научных целях. 


\section{Таблица 1}

Распространенность сопутствующей патологии и основные биохимические показатели в основной и контрольной группе

Table1

Prevalence of comorbidity and main biochemical parameters in the main and control groups

\begin{tabular}{|l|c|c|}
\hline \multicolumn{1}{|c|}{$\begin{array}{c}\text { Название сопутствующего } \\
\text { заболевания }\end{array}$} & Пациенты с ВМД, $\mathrm{n}=57$ & Пациенты без ВМД, $\mathrm{n}=52$ \\
\hline $\begin{array}{l}\text { Артериальная гипертензия } \\
\text { степени }\end{array}$ & $5,3 \pm 2,9$ & $7,7 \pm 3,7$ \\
\hline ИБС & $63,2 \pm 6,4$ & $61,5 \pm 6,7$ \\
\hline Сахарный диабет IІ-го типа & $5,3 \pm 2,9$ & $5,7 \pm 3,2$ \\
\hline $\begin{array}{l}\text { Нарушение толерантности к } \\
\text { глюкозе }\end{array}$ & $3,5 \pm 2,4$ & $3,8 \pm 2,6$ \\
\hline Болезни органов дыхания & $56,4 \pm 6,6$ & $50,0 \pm 6,8$ \\
\hline Желчнокаменная болезнь & $12,2 \pm 4,3$ & $15,2 \pm 5,0$ \\
\hline Мочекаменная болезнь & $24,6 \pm 5,6$ & $19,0 \pm 5,4$ \\
\hline $\begin{array}{l}\text { Острые нарушения мозгового } \\
\text { кровообращения }\end{array}$ & $2,5 \pm 2,4$ & $1,9 \pm 1,8$ \\
\hline Общий холестерин, ммоль/л & $4,7 \pm 0,5$ & $4,9 \pm 0,4$ \\
\hline Триглицериды, ммоль/л & $1,6 \pm 0,2$ & $1,7 \pm 0,3$ \\
\hline ЛПВП, ммоль/л & $1,2 \pm 0,1$ & $1,3 \pm 0,2$ \\
\hline ЛПНП, ммоль/л & $2,4 \pm 0,5$ & $2,2 \pm 0,3$ \\
\hline Глюкоза, ммоль/л & $5,0 \pm 0,9$ & $5,3 \pm 0,7$ \\
\hline
\end{tabular}

При статистической обработке полученных результатов применялась программа «Statistica 6.0» для выявления корреляционных связей, считавшихся достоверными при $\mathrm{P} \leq 0,05$. Оценка достоверности различий выполнилась по непараметрическому критерию Т-Уайта.

Результаты и их обсуждение. У больных ВМД AREDS-4 пожилого возраста в сравнении с возрастным контролем установлены статические значимые отклонения по всем изученным сывороточным интерлейкинам (табл. 1). Однако содержание системных провоспалительных интерлейкинов при развитии ВМД 4-й стадии характеризуется значительным повышением, а противовоспалительных интерлейкинов - существенным снижением по отношению к группе возрастного контроля. Среди провоспалительных интерлейкинов крови максимальный подъем у пациентов основной группы выявлен для IL-1 $\beta$ и IL-8, имеющих многократное и практически эквивалентное увеличение. Уровень других провоспалительных интерлейкинов IL-2 и
IL-6, IL-18 в сыворотке крови больных ВМД 4-й стадии повысился в меньшей степени. Содержание TNF- $\alpha$ среди пациентов с рассматриваемой патологией также увеличилось $(\mathrm{p}<0,01)$.

Среди противовоспалительных интерлейкинов у больных ВМД 4-й стадии отмечается в сравнении с контрольной группой статистически значимое снижение в сыворотке крови (табл. 2). При этом наибольшее уменьшение свойственно IL-4, уровень которого понизился более чем в 3 раза $(\mathrm{P}<0,001)$. Вторым по величине снижения в группе провоспалительных интерлейкинов является IL-10. Содержание IFN- $\alpha$ с ВМД 4-й стадии достоверно уменьшилось против лиц контроля $(\mathrm{P}<0,001)$.

Анализ нарушений в оксидантной системе крови больных ВМД 4-й стадии выявил статистически значимое в сравнении с возрастным контролем повышение всех показателей свободно-радикального окисления липидов (табл. 3). Увеличение малонового диальдегида на системном 
уровне у больных с ВМД 4-й стадии является наивысшим, что указывает на его первостепенное значение в генезе обсуждае- мой патологии глаза. В наименьшей степени в основной группе повысилось содержание гидроперекисей липидов $(\mathrm{P}<0,001)$.

Таблица 2

\section{Уровень сывороточных интерликинов у пациентов с ВМД 4-й стадии в сравнении с контрольной группой $(\mathrm{M} \pm \mathrm{m}$, пг/мл)}

Table 2

Serum interleukin levels in patients with stage 4 age-related macular degeneration compared to the control group $(M \pm m, p g / m l)$

\begin{tabular}{|c|c|c|c|}
\hline $\begin{array}{c}\text { Интерлейкин } \\
\text { крови }\end{array}$ & $\begin{array}{c}\text { Больные ВМД 4-й стадии в } \\
\text { возрасте 60-75лет, } \mathrm{n}=57\end{array}$ & $\begin{array}{c}\text { Люди в возрасте 60-75 } \\
\text { лет без БМД, } \mathrm{n}=52\end{array}$ & $\mathrm{P}$ \\
\hline IL-1/3 & $35,6 \pm 2,2$ & $3,4 \pm 0,8$ & $<0,001$ \\
\hline IL-2 & $59,7 \pm 3,1$ & $16,2 \pm 1,3$ & $<0,001$ \\
\hline IL-4 & $1,8 \pm 0,4$ & $5,7 \pm 0,7$ & $<0,001$ \\
\hline IL-6 & $6,7 \pm 0,8$ & $4,0 \pm 0,5$ & $<0,001$ \\
\hline IL-8 & $524,3 \pm 14,2$ & $48,4 \pm 3,6$ & $<0,001$ \\
\hline IL-10 & $6,2 \pm 0,5$ & $16,5 \pm 1,4$ & $<0,001$ \\
\hline I1-18 & $121,4 \pm 3,8$ & $38,3 \pm 2,2$ & $<0,001$ \\
\hline TNF- $\alpha$ & $9,6 \pm 0,7$ & $5,2 \pm 0,6$ & $<0,01$ \\
\hline IFN- $\alpha$ & $16,8 \pm 1,0$ & $32,5 \pm 0,8$ & $<0,001$ \\
\hline IFN-- & $4,9 \pm 0,4$ & $11,7 \pm 0,6$ & $<0,001$ \\
\hline
\end{tabular}

Состояние оксидантной системы крови при ВМД 4-й стадии

Таблииа 3 и в контрольной группе $(M \pm m)$

Table3

State of the blood oxidant system in age-related macular degeneration stage 4 and in the control group

\begin{tabular}{|l|c|c|c|}
\hline $\begin{array}{l}\text { Показатель перекисного } \\
\text { окисления липидов }\end{array}$ & $\begin{array}{c}\text { Больные ВМД 4-й стадии } \\
\text { в возрасте 60-75лет, } \mathrm{n}=57\end{array}$ & $\begin{array}{c}\text { Люди в возрасте 60-75 } \\
\text { лет без БМД, } \mathrm{n=52}\end{array}$ & $\mathrm{P}$ \\
\hline $\begin{array}{l}\text { Гидроперекиси липи- } \\
\text { дов, отн.ед. }\end{array}$ & $79,2 \pm 1,3$ & $70,3 \pm 0,8$ & $<0,001$ \\
\hline $\begin{array}{l}\text { Диеновые конъюгаты, } \\
\text { отн.ед. }\end{array}$ & $5,4 \pm 0,6$ & $2,1 \pm 0,2$ & $<0,001$ \\
\hline $\begin{array}{l}\text { Малоновый диальдегид, } \\
\text { мкмоль/л }\end{array}$ & $10,8 \pm 0,9$ & $2,4 \pm 0,3$ & $<0,001$ \\
\hline
\end{tabular}

Корреляционный метод у больных с ВМД 4-й стадии показал наличие прямых достоверных связей IL-1 $\beta$ с уровнем малонового диальдегида $(\mathrm{r}=+0,786, \mathrm{P}<0,01)$, диеновых коньюгат $(\mathrm{r}=+0,542, \mathrm{P}<0,01)$ и гидроперекисей липидов $(\mathrm{r}=+0,186$, $\mathrm{P}>0,05)$.Изменение сывороточного IL-8 находится в прямой корреляционной связи с содержанием в крови малонового диальдегида $(\mathrm{r}=+0,824, \mathrm{P}<0,001)$, диеновых коньюгат $(\mathrm{r}=+0,613, \mathrm{P}<0,01)$ и гидропереки- сей липидов $(\mathrm{r}=0,208, \mathrm{P}<0,05)$. Средние прямые корриляционные связи установлены также между IL-2, IL-18 и показателями системного свободнорадикального окисления $(\mathrm{P}<0,05)$, за исключением гидропереписей липидов. Между уровнем противовоспалительных интерлейкинов (IL-4, IL-10) и показателями оксидатного статуса больных ВМД 4-й стадии обнаружена обратная зависимость. Так, сывороточный IL-4, имеет обратную среднюю 
корреляционную связь с уровнем малонового диальдегида в крови $(\mathrm{r}=-0,467$, $\mathrm{P}<0,05)$ и диеновых коньюгат $(\mathrm{r}=-0,502$, $\mathrm{P}<0,05)$. Изменение IL-10 в сыворотке крови у пациентов с изученной патологией коррелирует с малоновым диальдегидом $(\mathrm{r}=-0,513, \mathrm{P}<0,01)$ и гидроперекисью липидов $(\mathrm{r}=-0,325, \mathrm{P}<0,05)$. Корреляционные связи других интерлейкинов, интерферонов и показателей перекисного окисления липидов при ВМД недостоверны.

Следовательно, далекозашедшая стадия (AREDS-4) ВМД ассоциируется с нарастанием системной провоспалительной реакции - повышением выработки всех провоспалительных интерлейкинов и выраженной селективной гиперсекрецией IL-1 $\beta$ и IL-8, способствующих, по мнению $[17,18]$, нарастанию локальных ангиогенных эффектов, характерных для поздней 4-й стадии ВМД. Именно эти изменения, на наш взгляд, обусловливают активацию иммунопатологических реакций, что соответствует концепции воспаления в развитии ВМД $[17,18]$. Иммунологические нарушения и пожилой возраст играют существенную роль в возникновении и развитии ВМД [14].

Важнейшим фактором в патогенезе ВМД является и усиление процессов свободнорадикального окисления липидов, выявленное нами в виде достоверного повышения гидроперекисей липидов, диеновых конъюгат и малонового диальдегида. Это согласуется с данными Мякотных В.С. и др. [19], установивших, что в пожилом возрасте увеличивается уровень диеновых конъюгат в крови и значительно снижаются показатели антиоксидантной системы в 61-70 лет.

Заключение. Формирование далеко зашедшей стадии ВМД в пожилом возрасте сопровождается существенным повышением всех провоспалительных интерлейкинов и показателей оксидатного статуса на системном уровне. Напротив, продукция противовоспалительных интерлейкинов у больных ВМД пожилого возраста достоверно снижается. Изменения IL-1 $\beta$, IL-8,Il-2,IL-18 имеют прямые корреляци- онные связи с показателями системного свободорадикального окисления. Уровень противовоспалительных интерлейкинов (IL-4 и IL-10) находится в обратной зависимости с содержанием продуктов перекисного окисления липидов. Следовательно, развитие 4-й стадии ВМД ассоциируется прежде всего с сывороточными IL-1 $\beta$, IL-8, IL-4, IL-10, малоновым диальдегидом и диеновыми конъюгатами. Полученные результаты следует использовать в гериатрической практике при рацианализации диагностики и терапии больных с далекозашедшей ВМД.

В отнотении данной статьи не было зарегистрировано конфликта интересов.

\section{Список литературы}

1. Абдулаева Э.А. Роль системы комплемента и других воспалительных факторов в развитии возрастной макулярной дегенерации // Казанский медицинский журнал. 2018. $\begin{array}{llll}\text { T. 99, N } 4 . & \text { C. 657-664. }\end{array}$ https://doi.org/10.17816/KMJ2018-657

2. Телегина Д.В., Кожевникова О.С., Колосова Н.Г. Молекулярные механизмы гибели клеток в сетчатке при развитии возрастной молекулярной дегенерации // Успехи геронтологии. 2016. Т. 29, N 3. С. 424-432.

3. Тур Е.В., Кузнецов А.А., Быстров А.М. Оценка уровня цитокинов слезы у пациентов с неоваскулярной возрастной макулярной дегенерацией // Российский иммунологический журнал. 2016. Т. 10(19), N 3. C. 361-362.

4. Comparison of Clinical Trial and Systematic Review Outcomes for the 4 Most Prevalent Eye Diseases / I.J. Saldanha [et al.] // JAMA Ophthalmol. 2017. Vol. 135, N 9. P. 933-940. DOI: 10.1001/jamaophthalmol.2017.2583

5. Characteristics of symptoms experienced by persons with dry eye disease while driving in China / Y. Wang [et al.] // Eye (Lond). 2017. Vol. 31, N 11. P. 1550-1555. DOI: https://doi.org/10.1038/eye.2017.88

6. WHO. Prevention of Blindness and Visual Impairment. Priority Eye Diseases [Electronic]. $2017 . \quad$ URL: https://www.who.int/blindness/causes/priority/en/ index 7.html (дата обращения: 03.05.2018).

7. Present and possible therapies for agerelated macular degeneration / M. Khan [et al.] // ISRN ophthalmol. 2014. Vol. 2014. Article ID 
608390.

DOI:

http://dx.doi.org/10.1155/2014/608390

8. Akpek E.K., Smith R.A. Overview of age-related ocular conditions // Amer. J. Managed Care. 2013. Vol. 19, N 5. P. s67-s75.

9. Neighborhood Deprivationand Riskof Age-Related Eye Diseases: A Follow-up Studyin Sweden / T. Hamano [et al.] // Ophthalmic Epidemiol. 2015. Vol. 22, N 5. P. 308-320. DOI: https://doi.org/10.3109/09286586.2015.1056537

10. Nowak M.S., Smigielski J. The Prevalence of Age-Related Eye Diseases and Cataract Surgery among Older Adults in the City of Lodz // Poland J Ophthalmol. 2015. Vol. 2015. Article ID 605814

DOI: https://doi.org/10.1155/2015/605814

11. Prevalence of age-related macular degeneration in elderly Caucasians: the Tromso eye study / M.G. Erke [et al.] // Ophthalmology. 2012. Vol. 119, N 9. P. 1737-1743. DOI: https://doi.org/10.1016/j.ophtha.2012.03.016

12. Prevalence and pattern of vitreo-retinal diseases in Nepal: the Bhaktapur glaucoma study / S.S. Thapa [et al.] // BMC Ophthalmology. 2013. Vol. 13, P. 9. DOI: https://doi.org/10.1186/14712415-13-9

13. Коняев Д.А. Медико-эпидемиологический анализ заболеваемости и анти-VEGF лечения экссудативной формы возрастной макулярной дегенерации в Тамбовской области за 6 лет // Вестн. Тамбовского Университета. 2016. T. 21. C. $1583-1586$.

14. Ambati J., Atkinson J.P., Gelfand B.D. Immunology of age-related macular degeneration // Nature Reviews Immunology. 2013. Vol. 13. P. 438-451. DOI: https://doi.org/10.1038/nri3459

15. Penfold P.L. Inflammation and agerelated macular degeneration // JAMA. 2004. Vol. 291, N 6. P. 704-710.

16. Zarbin M.A. Current concepts in the pathogenesis of age - related macular degenerationes // Archives of Ophthalmology. 2004. Vol. 122, N $4 . \quad$ P. 598-614. $\quad$ DOI: 10.1001/archopht.122.4.598

17. Immunological and aetiological aspects of macular degeneration / P.L. Penfold [et al.] // Prog. Retin. Eye. Res. 2001. Vol. 20, N 3. P. 385414. DOI: https://doi.org/10.1016/S13509462(00)00025-2

18. Penfold P.L. Inflammation and agerelated macular degeneration // JAMA. 2004. Vol. 291, N $6 . \quad$ P. 704-710. DOI: 10.1001/jama.292.1.43-a
19. Сравнительная биохимия процесса старения мужчин и женщин / В.С. Мякотных [и др.] // Успехи геронтологии. 2014. Т. 27, N 4. C.612-620.

\section{References}

1. Abdullayeva EA. [The Role of complement system and other inflammatory factors in the development of age-related macular degeneration]. Kazanskij medicinskij zhurnal. 2018;99(4):657-664. Russian. DOI: https://doi.org/10.17816/KMJ2018-657

2. Telegina DV, Kozhevnikova OS, Kolosova NG. [Molecular mechanisms of cell death in the retina in the development of age-related molecular degeneration]. Uspekhi gerontologii. 2016;29(3):424-432. Russian

3. Tur EV, Kuznetsov AA, Bystrov AM. [Evaluation of tear cytokine level in patients with neovascular age-related macular degeneration]. Rossijskij immunologicheskij zhurnal. 2016;10(19)(3):361-362. Russian

4. Saldanha IJ, Lindsley K, Do DV, et al. Comparison of Clinical Trial and Systematic Review Outcomes for the 4 Most Prevalent Eye Diseases. JAMA Ophthalmol. 2017;135(9):933-940. DOI: 10.1001/jamaophthalmol.2017.2583

5. Wang Y, Lv H, Liu Y, et al. Characteristics of symptoms experienced by persons with dry eye disease while driving in China. Eye (Lond). 2017 June 16;31(11):1550-1555. DOI: https://doi.org/10.1038/eye.2017.88

6. WHO. Prevention of Blindness and Visual Impairment. Priority Eye Diseases [Internet]. 2017 [cited 2018 May 03]. Available from: https://www.who.int/blindness/causes/priority/en/i ndex7.html.

7. Khan M, Agarwal K, Loutfi M, et al. Present and possible therapies for age-related macular degeneration. ISRN ophthalmol. 2014 Apr;2014:608390.

DOI: http://dx.doi.org/10.1155/2014/608390

8. Akpek EK, Smith RA. Overview of agerelated ocular conditions. Amer. J. Managed Care. 2013 May;19(5):s67-s75.

9. Hamano T, Li X, Tanito M, et al. Neighborhood Deprivationand Riskof Age-Related Eye Diseases: A Follow-up Studyin Sweden. Ophthalmic Epidemiol. 2015 Sep 23;22(5):308-320. DOI: https://doi.org/10.3109/09286586.2015.1056537

10. Nowak MS, Smigielski J. The Prevalence of Age-Related Eye Diseases and Cataract Surgery among Older Adults in the City of Lodz. 
Poland J Ophthalmol. 2015 Feb 19;2015:605814. DOI: https://doi.org/10.1155/2015/605814

11. Erke MG, Bertelsen G, Peto T, et al. Prevalence of age-related macular degeneration in elderly Caucasians: the Tromso eye study. Ophthalmology. 2012 Sep;119(9):1737-1743. DOI: https://doi.org/10.1016/j.ophtha.2012.03.016

12. Thapa SS, Thapa R, Paudyal I, et al. Prevalence and pattern of vitreo-retinal diseases in Nepal: the Bhaktapur glaucoma study. BMC Ophthalmology. 2013 March 28;13:9. DOI: https://doi.org/10.1186/1471-2415-13-9

13. Konyaev DA. [Medical and epidemiological analysis of morbidity and anti-VEGF treatment of exudative forms of age-related macular degeneration in the Tambov region for 6 years]. Vestn. Tambovskogo Universiteta. 2016;21:1583-1586. Russian.

14. Ambati J, Atkinson JP, Gelfand BD. Immunology of age-related macular degeneration. Nature Reviews Immunology. 2013 May 24;13:438-451.

DOI: https://doi.org/10.1038/nri3459

15. Penfold PL. Inflammation and agerelated macular degeneration. JAMA. 2004;291(6):704-710.

16. Zarbin MA. Current concepts in the pathogenesis of age - related macular degenerationes. Archives of Ophthalmology. 2004;122(4):598-614. DOI: 10.1001/archopht.122.4.598

17. Penfold PL, Madigan MC, Gillies MC, et al. Immunological and aetiological aspects of macular degeneration. Prog. Retin. Eye. Res. 2001
May;20(3):385-414.

DOI: https://doi.org/10.1016/S1350-

9462(00)00025-2

18. Penfold PL. Inflammation and agerelated macular degeneration. JAMA. 2004;291(6):704-710.

DOI: 10.1001/jama.292.1.43-a

19. Myakotnykh VS, Berezina DA, Borovkova TA, et al. [Comparative biochemistry of the aging process of men and women]. Advances in gerontology. 2014;27(4):612-620. Russian.

Статья поступила в редакцию 25 ноября 2019 г. Поступила после доработки 30 декабря 2019 г. Принята к печати 12 января 2020 г.

Received 25 November 2019

Revised 30 December 2019

Accepted 12 January 2020

\section{Информация об авторе}

Дмитрий Александрович Коняев, врачофтальмолог, заведующий операционным блоком, Тамбовский филиал ФГАУ МНТК «Микрохирургия глаза имени академика С.Н. Фёдорова», E-mail: vitalaxen@mail.ru.

\section{Information about the author}

Dmitry A. Konyaev, Ophthalmologist, Head of the Operating Unit, Academician S.N. Fedorov Eye Microsurgery Complex, Tambov Branch, E-mail: vitalaxen@mail.ru. 